\title{
Impact of Weight-Related Discrimination, Body Dissatisfaction and Self-Stigma on the Desire to Weigh Less
}

\author{
Franziska Jung a, b, c Jenny Spahlholz ${ }^{d}$ Anja Hilbert ${ }^{\text {a, e }}$ \\ Steffi G. Riedel-Heller ${ }^{f} \quad$ Claudia Luck-Sikorskia, b, c \\ ${ }^{a}$ Integrated Research and Treatment Center AdiposityDiseases (IFB), University of \\ Leipzig, Leipzig, Germany; ${ }^{b}$ Competence Cluster for Nutrition and Cardiovascular Health \\ (nutriCARD), Halle-Jena-Leipzig, Halle (Saale), Germany; ' ${ }^{C}$ niversity of Applied Sciences \\ SRH Gera, Gera, Germany; ${ }^{d}$ Institute of Rehabilitation Medicine, Martin-Luther University \\ Halle-Wittenberg, Halle (Saale), Germany; ${ }^{e}$ Department of Medical Psychology and

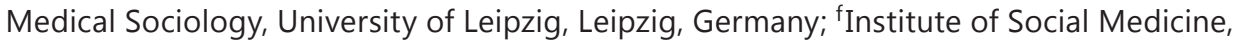 \\ Occupational Health and Public Health (ISAP), University of Leipzig, Leipzig, Germany
}

\section{Key Words}

Weight loss goals · Obesity $\cdot$ Stigma $\cdot$ Body dissatisfaction $\cdot$ Desired weight

\begin{abstract}
Aim: Currently, health care professionals plead for stabilization of weight and improving health conditions rather than focusing on weight loss only. Individuals with obesity have been shown to report weight loss goals that are much higher than what has been suggested by guidelines. The aim was to determine whether weight discrimination and body dissatisfaction have an impact on how much weight an individual with obesity wants to lose. Methods: In this representative telephone survey, 878 participants with obesity were asked about their experiences with weight stigma, their body image concerns, and about the amount of weight they would like to weigh using random digital dialing and Kish selection grid to ensure random selection of participants. Results: Regression analysis reveals that being female, having a higher BMI, being younger, and trying to lose weight was related to a greater discrepancy between current weight and desired weight. The discrepancy between current weight and desired weight was greater when participants reported discrimination due to their weight as well as internalized stigma and body image concerns. Conclusion: Independent on the weight loss method, treating obesity should include realistic weight loss goals without being affected by social pressure or weight stigma, especially since stigma can result in further weight gain and decline health issues related to obesity and overweight.
\end{abstract}


Jung et al.: Impact of Weight-Related Discrimination, Body Dissatisfaction and SelfStigma on the Desire to Weigh Less

\section{Introduction}

Effective and evidence-based obesity treatment options that work for every patient on a long-term basis are scarce. Clinical guidelines $[1,2]$ recommend a weight loss of $5-10 \%$. This allows individuals to adapt during the process of weight loss as well as afterwards since weight loss is associated with changes in one's body appearance and body image, but also affects mobility and comorbidity. Weight loss within this range can reduce the presence of cardiometabolic risk factors [3] and improve glucose metabolism [4]. By emphasizing modest weight loss, the guidelines try to shift the focus away from cosmetic reasons towards improving overall health. Even though research suggests that the focus should not be put on weight loss per se or rather plead in favor of a 'health-at-every-size' [5] or 'weight-inclusive' approach [6], patients as well as health care professionals still give priority to losing large amounts of weight or tend to overestimate the effect of lifestyle interventions, leading to unrealistically high weight loss goals and expectations. In one study, physicians rated a weight loss of $10.6 \%$ as 'disappointing' and a weight loss of $21.5 \%$ with a lifestyle-based intervention as 'acceptable' [7]. Patients suffering from excess weight have been shown to report weight loss goals that deviate tremendously from what has been suggested by guidelines [8-11]. For instance, in one study that included a large sample of (nonbariatric) participants seeking dietary advice or treatment, about $49 \%$ of all participants reported unrealistic weight loss goals [12]. Even though it has recently been shown that there is no association between weight loss outcomes and realistic weight loss goals compared to unrealistic ambitions [13], unsuccessful weight loss attempts have been shown to predict future weight gain and unhealthy weight cycling [14-16]. Having more modest weight loss goals that can realistically be reached might on the contrary be beneficial for losing weight in the long term, because 'reaching one's goal weight' is one of the main factors that can positively contribute to weight loss maintenance $[13,14]$. Unrealistic goals on the other hand can serve as a basis for disappointment and failure to reach these self-set goals and lead to several negative consequences. Indeed, greater desired weight loss strongly predicted the frequency of mentally and physically unhealthy days [17]. Most previous research on body dissatisfaction and weight loss has focused on individuals with normal weight or on adolescents, but not on adults with obesity. However, there is evidence that improving body image or body appearance (rather than health) may be an influential factor for weight loss desire $[19,20]$, since higher weight loss goals result from greater body image concerns among obese individuals in general, and among women with obesity in particular [21]. The perceived need of losing weight and the wish to achieve greater body weight reductions might be linked to anxiety about body image concerns [20, 23], resulting in disordered health behavior [22]. The question remains whether body image concerns are grounded on social or cultural floors, especially since higher levels of body dissatisfaction have been shown to be associated with social pressure to be slim [24]. In individuals with overweight or obesity, there seems to be a link between social unacceptability and weight stigma on the one hand and body image concerns on the other hand that may result in unhealthy desires to lose a lot of body weight $[25,26]$ due to maladaptive eating habits. Moreover, weight stigma can sometimes be self-directed by adopting negative weightbased attitudes or stereotypes [27]. Individuals who tend to internalize weight stigma often perceive their bodies as unattractive and in need of appearance modification to change their body size [28]. Previous studies [29-31] suggested that highly internalized weight bias can be associated with greater body image concern, anti-fat attitudes, depressive symptoms, stress, and reduced self-esteem. In Western societies for instance, individuals with obesity are often categorized as being lazy, unmotivated, or lacking willpower [32, 33]. Overweight or obesity is viewed as being controllable through willpower and effort. If these negative attitudes are internalized by those affected, it could give grounds to the belief that it might 
Jung et al.: Impact of Weight-Related Discrimination, Body Dissatisfaction and SelfStigma on the Desire to Weigh Less

Fig. 1. Detailed analysis of the response rate of the telephone interview. Note: Refusal: participant verbally refuses to give the interview or does not want to take part; Dropout: participant drops out during the interview; Answering machine: automatic machinery response; Non-contact: participant does not answer the phone despite free line signal.

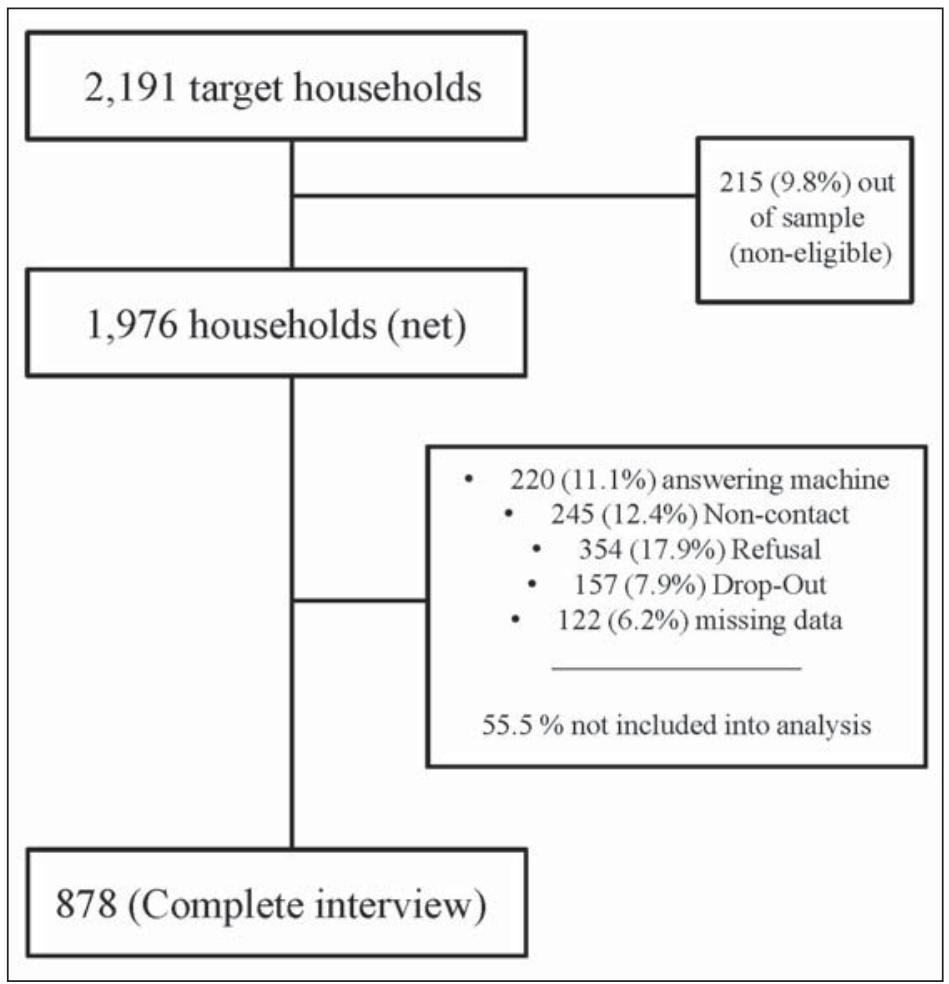

therefore be easily manageable to lose a lot of weight by putting in tremendous amounts of effort and pressure, hence resulting in unrealistic high weight loss goals. Instead of being motivated to achieve health and well-being, social pressure or social weight stigma can therefore result in a variety of negative health outcomes [34-36].

The question remains whether higher drive for thinness translates to a larger discrepancy between current and desired weight. This weight discrepancy can be considered as a proxy for weight loss goals and body dissatisfaction that arises from socially desired body shape standards and stems from experiences or internalization of weight bias. Therefore, the aim of this study was to determine whether internalized weight stigma, perceived discrimination, and negative body image can be linked to the discrepancy between current and desired weight. We hypothesize that people who feel discriminated because of their weight report a larger weight discrepancy and hence more extreme weight loss goals. Additionally, we hypothesize that individuals who appear to be dissatisfied with their body tend to wish for greater weight reductions compared to people who are more satisfied with their appearance.

\section{Material and Methods}

Overall, 2,191 target households were randomly selected from all German states. Respondents were verbally interviewed by FORSA, an independent institute for social research and statistical analysis, using computer-assisted telephone interviews (CATI) between January and February 2015. Participants were selected using random digital dialing and Kish selection grid when choosing the person in the household to carry out the survey with. The use of this method as well as standardization of the interview process ensured random selection of participants. Demographic weighing was applied by age, gender, and education to ensure representability of the general public.BM screening was based on self-reported weight and height and calculated using the standard formula. In order to avoid missing values, participants who refused to provide infor- 
Jung et al.: Impact of Weight-Related Discrimination, Body Dissatisfaction and SelfStigma on the Desire to Weigh Less

Table 1. Descriptive statistics of the original sample and the study sample

\begin{tabular}{|c|c|c|c|}
\hline & $\begin{array}{l}\text { Original sample } \\
(n=1,000)\end{array}$ & $\begin{array}{l}\text { Study sample } \\
(\mathrm{n}=878)\end{array}$ & $\begin{array}{l}\mathrm{p} \text { values } \\
\left(\chi^{2}, \mathrm{t} \text {-test }\right)\end{array}$ \\
\hline Mean age, years & $56.43 \pm 14.82$ & $56.46 \pm 14.47$ & 0.965 \\
\hline Gender & & & 0.830 \\
\hline Women & $448(44.80 \%)$ & $389(44.3 \%)$ & \\
\hline Men & $552(55.20 \%)$ & $489(55.7 \%)$ & \\
\hline Weight (BMI), $\mathrm{kg} / \mathrm{m}^{2}$ & $34.31 \pm 3.98$ & $34.35 \pm 3.98$ & 0.828 \\
\hline Women & $34.56 \pm 4.24$ & $34.59 \pm 4.25$ & \\
\hline BMI $30.0-34.9$ & $289(64.08 \%)$ & $249(64.01 \%)$ & \\
\hline BMI 35.0-39.9 & $116(25.72 \%)$ & $99(25.45 \%)$ & \\
\hline $\mathrm{BMI} \geq 40.0$ & $46(10.20 \%)$ & $41(10.54 \%)$ & \\
\hline Men & $34.11 \pm 3.74$ & $34.13 \pm 3.74$ & \\
\hline BMI $30.0-34.9$ & $375(68.30 \%)$ & $338(69.12 \%)$ & \\
\hline BMI 35.0-39.9 & $132(24.04 \%)$ & $116(23.72 \%)$ & \\
\hline $\mathrm{BMI} \geq 40.0$ & $41(7.47 \%)$ & $35(7.16 \%)$ & \\
\hline Education & & & 0.777 \\
\hline$<12$ years & $824(82.73 \%)$ & $722(82.23 \%)$ & \\
\hline$>12$ years & $172(12.27 \%)$ & $156(17.77 \%)$ & \\
\hline Mean discrepancy between actual weight and comfortable weight & $18.52 \pm 9.24$ & $18.76 \pm 9.40$ & 0.577 \\
\hline Mean discrepancy in \% (women) & $20.73 \pm 9.31$ & $18.71 \pm 9.29$ & 0.002 \\
\hline Mean discrepancy in \% (men) & $16.73 \pm 8.79$ & $18.57 \pm 9.34$ & 0.001 \\
\hline Are you currently trying to lose weight? & & & 0.569 \\
\hline Yes & $605(60.50 \%)$ & $543(61.85 \%)$ & \\
\hline No & $394(39.40 \%)$ & $335(38.15 \%)$ & \\
\hline WBIS $(\alpha=0.8251)(n=988)$ & & & 0.780 \\
\hline Overall score range $0-60$ & $17.29 \pm 11.89$ & $17.44 \pm 11.80$ & \\
\hline Lifetime discrimination $(\alpha=0.5407)$ & & & 0.858 \\
\hline 0 (= no discrimination) & $602(60.20 \%)$ & $525(59.79 \%)$ & \\
\hline 1 (= experiences of discrimination) & $398(39.80 \%)$ & $353(40.21 \%)$ & \\
\hline Daily discrimination $(\alpha=0.8382)(n=988)$ & & & 0.901 \\
\hline Overall score range $2-36$ & $10.85 \pm 3.48$ & $10.83 \pm 3.44$ & \\
\hline MBSRQ-AS $(\alpha=0.6452)(n=988)$ & & & 0.869 \\
\hline Overall score range $7-36$ & $23.93 \pm 3.92$ & $23.90 \pm 3.90$ & \\
\hline
\end{tabular}

mation on weight were given a specific weight range, being able to assign them to one of the BMI categories [37]. Overall, $n=1,000$ individuals participated in the assessment, corresponding to a response rate of $50.6 \%$ (fig. 1). Only participants with a BMI greater than $30 \mathrm{~kg} / \mathrm{m}^{2}$ were included in this study. Of the $\mathrm{n}=1,000$ assessments, 122 (12.2\%) were excluded from the detailed analyses due to missing data. Therefore, the following analyses were conducted with a representative sample of $n=878$ participants who were interviewed regarding their experiences with weight-related stigma. In terms of sample characteristics, there was no difference between the main sample $(n=1,000)$ and the study sample $(n=878)$ as can be seen in table 1 . The method of this study was approved by the Ethics Committee of the University of Leipzig (Approval No 208-14-14042014). 


\section{Instruments}

\section{Covariates}

Sociodemographic and other measures such as gender, age, education, monthly income, weight, and height were included as confounders in all analyses. Information on self-reported weight and height was used to calculate the participants' BMI (in $\mathrm{kg} / \mathrm{m}^{2}$ ). Additionally, participants were asked whether they are currently trying to lose weight (yes/no).

\section{Independent Variables: Stigma- and Body Image-Related scales}

Three scales were used to investigate whether or how the participants feel their excess body weight affects their life. The Weight Bias Internalization Scale (WBIS), was used to determine the level of internalized weight stigma by asking to what extent respondents apply negative stereotypes and self-statements about individuals with obesity to themselves [30]. The original WBIS scale includes 11 items on a 7-point rating-scale ( 1 = strongly disagree, 7 = strongly agree). A German translation of all items has been published showing good psychometric properties [38, 39]; however, as suggested by the literature [38, 39], one item was excluded from analysis due to its negative correlation. Higher scores represent more internalization of stigma.

In addition, questions from the National Survey of Midlife Development in the US (MIDUS) on selfperceived discriminatory experiences were included to determine how often participants have been confronted with discrimination in everyday life [40-42]. The Lifetime Discrimination Scale (taken from the first survey wave) asked 'In each of the following, have you ever been discriminated because of your body weight?'. For instance, one of the following items was 'You were not hired for a job'. In addition, three more items were added to the original scale [40] to specifically focus on weight-related discrimination which is underrepresented in the original scale targeting all types of discrimination. These three items were generated through extensive qualitative research prior to the survey. In-depth interviews were conducted with people with obesity, summarizing occasions of discrimination (unpublished results from personal interviews, $\mathrm{n}=$ 6). From these interviews, the most prevalent occasions were selected and included in the adapted Lifetime Discrimination Scale [43]. These items were: 'You received inappropriate comments from your family or friends'; 'You were prevented from leisure activities because of your weight', and 'You were prevented from everyday activities or leisure activities because of physical barriers in your environment'. The response format included yes or no and the scale consisted of 11 items overall. The Daily Discrimination Scale (taken from the second MIDUS survey wave) included 9 items with a 4-point-scale ( 1 = never, 2 = rarely, $3=$ sometimes, 4 = often), asking 'How often on a day-to-day basis do you experience each of the following types of discrimination?'. As an example, one of the items was 'You are treated with less respect than other people'. Both scales were translated from English to German and controlled back by three researchers independently. Higher scores represent greater perception of weight discrimination.

Body image was measured using the Appearance Evaluation Subscale (containing 7 items) from the Multidimensional Body Self-Relations Questionnaire-Appearance Scale (MBSRQ-AS) [44, 45]. As an example, one of the items was 'I feel physically unattractive'. The answering format includes a 5-point-scale $(1=$ not at all, 5 = entirely). A validated German translation of this scale was obtained from the literature $[46,47]$. Higher scores represent higher levels of body satisfaction. All independent variables were checked for multicollinearity after the regression analysis. The variance of inflation factors (VIFs) were all small enough to exclude intercorrelations.

\section{Dependent Variable: Weight Discrepancy}

In addition to self-reported weight and height, participants were also asked for their personal weight they would feel comfortable with. Weight discrepancy can be defined as the difference between the current weight and the weight they would desire to feel comfortable with.

\section{Data Analysis}

All calculations were performed by using STATA 13.1. for Windows (StataCorp LLC, College Station, TX, USA) [48]. The data were weighted by age, gender, and education to match the German general public. 
The dependent variable was the amount of weight discrepancy (difference between current weight and desired weight). Participants who wanted to weigh more or gave inconsistent answers (i.e., participants indicating that they were trying to lose weight but simultaneously wanted to weigh more) were excluded from the final analysis $(n=3)$. The discrepancy between current weight and desired weight was calculated in kilograms and also in percentage from current weight. Data from the Lifetime Discrimination Scale were dichotomized ('no discrimination' or 'experiences of discrimination') due to the distribution of answers (only a few participants reported more than one case of lifetime discrimination). For the Appearance Evaluation Subscale, the WBIS and the Daily Discrimination Scale sum scores were calculated. Weight discrepancy in percent was used as the predictor variable in a linear regression model as a continuous variable. The model contained the following covariates: whether participants were currently trying to lose weight (yes/no), net household income, educational background (' $\geq 12$ years' or ' $<12$ years'), BMI, and participants' age and gender. BMI categories were determined according to WHO conventions [49]. The three stigma-related scales and the body image scale were introduced as the independent variables of interest in four separate models. In addition to statistical significance ( $p$ values), effect sizes $\left(\eta^{2}\right)$ of the confounding variables and the independent variables have also been calculated from F-test statistics , as suggested by Smithson [50]. The effect size measured in $\eta^{2}$ gives the proportion of variance associated with the main effect (i.e., each independent variable under consideration) and varies from small $\left(\eta^{2} \geq 0.01\right)$ to large $\left(\eta^{2} \geq 0.14\right)$, according to rules of thumb given in the literature [51, 52]. A logistic regression analyses was conducted to further examine the adherence to the aforementioned guidelines (e.g., whether their desired goal weight exceeds the recommended weight loss goal of $10 \%$ ). The amount of weight discrepancy was dichotomized to indicate either 'recommended weight loss' (discrepancy between current weight and desired weight $=0-9.99 \%$ ) and 'not recommended weight loss' (discrepancy between current weight and desired weight $\geq 10.0 \%$ ).

\section{Results}

\section{Demographic Information and Prevalence of Discrimination}

Sample characteristics can be found in table 1. The mean age of the participants was 56.5 years, and $44.3 \%$ were female. On average, the mean BMI in this sample was $34.4 \mathrm{~kg} / \mathrm{m}^{2}$. The participants' desired weight was on average $18.8 \%$ lower than their current weight. In other words, participants in this study desired to lose $19 \mathrm{~kg}$ on average (SD $11.1 \mathrm{~kg}$ ). Almost twothirds of participants in this sample (approximately 62\%) were currently trying to lose weight. Table 1 also summarizes mean scores for the four scales under investigation (WBIS, Lifetime Discrimination Scale, Daily Discrimination Scale, MBSRQ-AS). About 40\% of all participants stated that they have been discriminated due to their weight at least once in their lives.

\section{Linear Regression Analysis}

In addition, table 2 shows the results of the linear regression analysis with weight discrepancy as the outcome variable and internalized stigma (WBIS), Lifetime Discrimination, Daily Discrimination as well as appearance evaluation (MBSRQ-AS) as the four predictor variables. Effect sizes can be found in table 2 accordingly. Gender, BMI, age as well as current weight loss efforts significantly contributed to all four models. In other words, being female, having a higher BMI, being younger, and trying to lose weight were related to a greater discrepancy between current weight and desired weight. Regression diagnostics revealed that WBIS, Lifetime Discrimination, Daily Discrimination as well as MBSRQ-AS scores were significantly associated with this discrepancy. The more stigma has been internalized by an individual (Model 1a: $F(7,870)=49.15, p<0.001$, adjusted $R^{2}=0.2508$ ), the greater the discrepancy between current weight and desired weight. Similarly, a higher prevalence of being discriminated due to body weight (Model $2 \mathrm{a}: \mathrm{F}(7,870)=46.65, \mathrm{p}<0.001$, adjusted $\mathrm{R}^{2}=0.2385$, and 
Jung et al.: Impact of Weight-Related Discrimination, Body Dissatisfaction and SelfStigma on the Desire to Weigh Less

Table 2. Coefficients, effect sizes $\left(\eta^{2}\right)$ and $p$ values for the regression analysis with discrepancy between current weight and desired weight as the dependent variable $(\mathrm{n}=878)$, separated into Model 1a (WBIS), Model 2a (lifetime discrimination), Model 3a (daily discrimination) and Model 4a (MBSRQ-AS)

\begin{tabular}{|c|c|c|c|c|}
\hline Independent variable & $\begin{array}{l}\text { Model 1a } \\
\text { (effect size) }\end{array}$ & $\begin{array}{l}\text { Model } 2 \mathrm{a} \\
\text { (effect size) }\end{array}$ & $\begin{array}{l}\text { Model 3a } \\
\text { (effect size) }\end{array}$ & $\begin{array}{l}\text { Model 4a } \\
\text { (effect size) }\end{array}$ \\
\hline Gender $($ ref $=$ male $)$ & $\begin{array}{l}0.228^{* * *} \\
(0.111)\end{array}$ & $\begin{array}{l}0.253^{* * *} \\
(0.073)\end{array}$ & $\begin{array}{l}0.249 * * * \\
(0.120)\end{array}$ & $\begin{array}{l}0.234^{* * *} \\
(0.088)\end{array}$ \\
\hline BMI & $\begin{array}{l}0.059 * * * \\
(0.186)\end{array}$ & $\begin{array}{l}0.058 \text { *** } \\
(0.138)\end{array}$ & $\begin{array}{l}0.061^{* * *} \\
(0.178)\end{array}$ & $\begin{array}{l}0.058^{* * *} \\
(0.160)\end{array}$ \\
\hline Age & $\begin{array}{l}-0.007^{* * *} \\
(0.048)\end{array}$ & $\begin{array}{l}-0.007^{* * *} \\
(0.016)\end{array}$ & $\begin{array}{l}-0.008^{* * *} \\
(0.072)\end{array}$ & $\begin{array}{l}-0.008^{* * *} \\
(0.041)\end{array}$ \\
\hline Currently trying to lose weight (ref $=$ yes) & $\begin{array}{l}-0.184^{* * *} \\
(0.043)\end{array}$ & $\begin{array}{l}-0.231^{* * *} \\
(0.030)\end{array}$ & $\begin{array}{l}-0.237^{* * *} \\
(0.026)\end{array}$ & $\begin{array}{l}-0.230^{* * *} \\
(0.034)\end{array}$ \\
\hline Income & $\begin{array}{l}0.001 \\
(0.040)\end{array}$ & $\begin{array}{l}-0.002 \\
(0.003)\end{array}$ & $\begin{array}{l}-0.002 \\
(0.055)\end{array}$ & $\begin{array}{l}-0.002 \\
(0.027)\end{array}$ \\
\hline Education (ref = less than 12 years) & $\begin{array}{l}-0.065 \\
(0.040)\end{array}$ & $\begin{array}{l}-0.081 \\
(0.003)\end{array}$ & $\begin{array}{l}-0.074 \\
(0.052)\end{array}$ & $\begin{array}{l}-0.073 \\
(0.028)\end{array}$ \\
\hline WBIS & $\begin{array}{l}0.010 * * * \\
(0.027)\end{array}$ & & & \\
\hline Lifetime discrimination & & $\begin{array}{l}0.131^{* *} \\
(0.009)\end{array}$ & & \\
\hline Daily discrimination & & & $\begin{array}{l}0.011^{*} \\
(0.006)\end{array}$ & \\
\hline MBSRQ-AS & & & & $\begin{array}{l}-0.018^{* * *} \\
(0.015)\end{array}$ \\
\hline $\begin{array}{l}\text { ref }=\text { Reference variable for regression } \\
\text { Multidimensional Body Self-Relations Que } \\
\text { The dependent variable was logarithmi } \\
{ }^{*} p<0.05 ;{ }^{* *} p<0.01 ;{ }^{* * *} p<0.001 .\end{array}$ & $\begin{array}{l}\text { lysis; WBIS= } \\
\text { inaire-Appear } \\
\text { as it followed }\end{array}$ & $\begin{array}{l}\text { ight Bias Inte } \\
\text { ce Scale. } \\
\text { proximately a }\end{array}$ & $\begin{array}{l}\text { nalization Sca } \\
\text { log-normal dis }\end{array}$ & $\begin{array}{l}\text { MBSRQ-AS } \\
\text { ribution. }\end{array}$ \\
\hline
\end{tabular}

Model 3a: $F(7,870)=44.30, p<0.001$, adjusted $R^{2}=0.2338$ ), was associated with a higher discrepancy between current weight and desired weight. Finally, the more uncomfortable individuals feel with their body (Model $4 \mathrm{a}: \mathrm{F}(7,870)=42.75, \mathrm{p}<0.001$, adjusted $\mathrm{R}^{2}=0.2425$ ), the greater the discrepancy between current weight and desired weight.

With regard to correlations between dependent variables and covariates, small correlations have been found between BMI and all four dependent variables (WBIS: $r=0.1594$; lifetime discrimination: $r_{\mathrm{pbis}}=0.2698$; daily discrimination: $r=0.1648$; MBSRQ-AS: $r=$ -0.2197 ) as well as between 'currently trying to lose weight' and all four dependent variables (WBIS: $r_{\mathrm{pbis}}=-0.2336$; lifetime discrimination: $\chi^{2}=12.4288$; daily discrimination: $r_{\mathrm{pbis}}=$ -0.0503; MBSRQ-AS: $\mathrm{r}_{\mathrm{pbis}}=0.0708$ ).

\section{Logistic Regression Analysis}

With regard to the logistic regression analysis with the categorized discrepancy as the outcome variable, results are summarized in table 3 . The results show that gender, BMI, and age significantly influence the categorized discrepancy between current weight and desired weight in Model 1b $\left(\chi^{2}(7)=103.94, p<0.001\right.$, WBIS $)$, Model 2b $\left(\chi^{2}(7)=97.18, p<0.001\right.$; Lifetime Discrimination), Model $3 \mathrm{~b}\left(\chi^{2}(7)=88.03, \mathrm{p}<0.001\right.$; Daily Discrimination) and Model $4 \mathrm{~b}\left(\chi^{2}(7)=94.11, \mathrm{p}<0.001 ;\right.$ MBSRQ-AS $)$. 
Jung et al.: Impact of Weight-Related Discrimination, Body Dissatisfaction and Self-

Stigma on the Desire to Weigh Less

Table 3. Odds ratios, confidence intervals (95\%) and p values for logistic regression analysis with the categorized discrepancy between current weight and desired weight as the dependent variable ( $n=878)$, separated into Model 1b (WBIS), Model 2b (Lifetime Discrimination), Model 3b (Daily Discrimination) and Model 4b (MBSRQ-AS)

\begin{tabular}{|c|c|c|c|c|}
\hline Independent variable & $\begin{array}{l}\text { Model 1b } \\
\text { OR, p-value } \\
\text { (lower; upper) }\end{array}$ & $\begin{array}{l}\text { Model 2b } \\
\text { OR, p-value } \\
\text { (lower; upper) }\end{array}$ & $\begin{array}{l}\text { Model 3b } \\
\text { OR, p-value } \\
\text { (lower; upper) }\end{array}$ & $\begin{array}{l}\text { Model 4b } \\
\text { OR, p-value } \\
\text { (lower; upper) }\end{array}$ \\
\hline Gender $($ ref $=$ male $)$ & $\begin{array}{l}2.560 * * * \\
(1.747 ; 3.751)\end{array}$ & $\begin{array}{l}2.742^{* * *} \\
(1.876 ; 4.006)\end{array}$ & $\begin{array}{l}2.682^{* * *} \\
(1.838 ; 3.913)\end{array}$ & $\begin{array}{l}2.574 * * * \\
(1.759 ; 3.766)\end{array}$ \\
\hline BMI & $\begin{array}{l}1.323^{* * *} \\
(1.221 ; 1.433)\end{array}$ & $\begin{array}{l}1.312 \text { *** } \\
(1.211 ; 1.421)\end{array}$ & $\begin{array}{l}1.324^{* * *} \\
(1.223 ; 1.432)\end{array}$ & $\begin{array}{l}1.310^{* * *} \\
(1.210 ; 1.417)\end{array}$ \\
\hline Age & $\begin{array}{l}0.971 * * \\
(0.958 ; 0.985)\end{array}$ & $\begin{array}{l}0.972 * * \\
(0.958 ; 0.986)\end{array}$ & $\begin{array}{l}0.970 * * * \\
(0.956 ; 0.984)\end{array}$ & $\begin{array}{l}0.969 * * * \\
(0.956 ; 0.983)\end{array}$ \\
\hline Currently trying to lose weight (ref = yes) & $\begin{array}{l}0.802 \\
(0.556 ; 1.157)\end{array}$ & $\begin{array}{l}0.710^{*} \\
(0.497 ; 1.014)\end{array}$ & $\begin{array}{l}0.681^{*} \\
(0.478 ; 0.970)\end{array}$ & $\begin{array}{l}0.695^{*} \\
(0.487 ; 0.991)\end{array}$ \\
\hline Income & $\begin{array}{l}0.932 \\
(0.859 ; 1.010)\end{array}$ & $\begin{array}{l}0.932 \\
(0.860 ; 1.011)\end{array}$ & $\begin{array}{l}0.925 \\
(0.853 ; 1.003)\end{array}$ & $\begin{array}{l}0.926 \\
(0.855 ; 1.003)\end{array}$ \\
\hline Education (ref = less than 12 years) & $\begin{array}{l}1.050 \\
(0.651 ; 1.695)\end{array}$ & $\begin{array}{l}0.974 \\
(0.604 ; 1.569)\end{array}$ & $\begin{array}{l}0.991 \\
(0.617 ; 1.592)\end{array}$ & $\begin{array}{l}1.012 \\
(0.628 ; 1.630)\end{array}$ \\
\hline WBIS & $\begin{array}{l}1.039 * * * \\
(1.016 ; 1.061)\end{array}$ & & & \\
\hline Lifetime Discrimination & & $\begin{array}{l}1.698^{*} \\
(1.144 ; 2.519)\end{array}$ & & \\
\hline Daily Discrimination & & & $\begin{array}{l}1.013 \\
(0.945 ; 1.084)\end{array}$ & \\
\hline MBSRQ-AS & & & & $\begin{array}{l}0.957 * \\
(0.919 ; 0.997)\end{array}$ \\
\hline $\begin{array}{l}\mathrm{OR}=\text { odds ratio; } \text { ref }=\text { reference variable } \\
=\text { Multidimensional Body Self-Relations } \mathrm{Qu} \\
\text { Discrepancy between current weight an } \\
\text { lower than } 10 \% ; 1=\text { not recommended we } \\
{ }^{*} \mathrm{p}<0.05 ;{ }^{* *} \mathrm{p}<0.01 ;{ }^{* *} \mathrm{p}<0.001 .\end{array}$ & $\begin{array}{l}\text { ogistic regression } \\
\text { onnaire-Appeara } \\
\text { sired weight was } \\
\text { loss, greater thar }\end{array}$ & $\begin{array}{l}\text { alysis; WBIS = W } \\
\text { Scale. } \\
\text { egorized into tw } \\
\% \text { ) }\end{array}$ & $\begin{array}{l}\text { Bias Internaliz } \\
\text { gories }(0=\text { reco }\end{array}$ & $\begin{array}{l}\text { Scale; MBSRQ-A } \\
\text { ended weight loss }\end{array}$ \\
\hline
\end{tabular}

In terms of stigma and appearance evaluation, only three variables were significantly associated with the categorized discrepancy between current weight and desired weight. The more stigma was internalized ( $<<0.001$, WBIS, Model 1b), the higher perceptions of discrimination at least once in their lives ( $p=0.009$, Lifetime Discrimination, Model $2 b)$, and the greater individuals were unsatisfied with their appearance ( $p=0.004$, MBSRQ-AS, Model 4b), the greater the weight discrepancy. In terms of Daily Discrimination ( $p=0.722$, n.s., Model $3 b)$, no significant relationship was found. In order to investigate possible interaction effects, it was tested whether adding MBSRQ-AS as a moderator variable (i.e., weight bias internalization $\times$ body appearance) to the effect of stigmatization and discrimination had an influence on this regression analysis. The same was tested using the discrimination scale as the moderator variable. However, no significant results could be obtained.

\section{Discussion}

The intention of this study was to investigate whether stigmatization, internalization, and body image have an influence on weight discrepancy. In terms of weight discrimination, $40 \%$ of all participants in our sample stated that they have been discriminated due to their 
weight at least once in their lives. This goes align with recent findings from a meta-analysis on obesity and discrimination [53]. Our results reveal that female participants, younger participants, and participants with higher BMIs wanted to lose more weight than their counterparts, going align with the literature $[12,18,23]$. The discrepancy between current weight and desired weight was greater when participants reported discrimination due to their weight as well as internalized stigma. The same was true when participants reported body image concern: being unsatisfied with one self's body image due to being obese resulted in greater weight loss desires. Hence, we identified several variables associated with nonrecommended weight goals, among them the perception of social exclusion and societal influences. This goes align with research from a different population [54] showing that individuals assume that one's body can be reshaped on command and that effects of dieting (or weight loss) exceed that of weight loss per se, leading to increased attractiveness, health and popularity, hence giving grounds to setting unrealistic weight loss goals. Dieters often believe that weight loss will change their image from 'lazy' to 'self-controlled, ambitious or successful' [55]. In this context, several models might explain these associations: the cognitive-behavioral model and the dual pathway model. The first one argues that dissatisfaction with one's current shape or body weight fosters dieting behaviors and related cognitions in order to change one's appearance [56], which in turn could lead to binge eating when dieting efforts are disturbed [57]. The second model proposes that both body dissatisfaction and negative affect encourage eating disorders [58]. Becoming aware of sociocultural pressure to meet expectations of being thin might therefore promote body image concerns. As reviewed recently [8], focusing on weight reductions as the predominant goal ('weight-normative approach') is linked to weight discrimination and internalized weight stigma and might lead to weight regain, weight cycling, and negative psychological outcomes such as developing eating disorders due to failed weight loss attempts. Perceived and internalized weight stigma negatively influence eating behavior, resulting in a greater drive for thinness [24, 31], higher body dissatisfaction [31] as well as increased presence of binge eating episodes [24]. Internalized stigma has been shown to be stressful, and it may contribute to negative physical [59] and psychological health issues [62]. One very recent study has shown that it mediates the relationship between weight stigma and disordered eating behavior, indicating that it is important to address this issue in a clinical setting or as part of obesity care management [60]. The fact that self-directed weight stigma is related to increased presence of binge eating disorders $[29,58,61]$ elucidates one of the findings of the current study that higher levels of self-directed weight stigma make individuals with obesity want to lose much more weight as has been recommended by health professionals and guidelines.

The topic is of particular clinical relevance since having unrealistic weight loss goals can have negative consequences on treatment success as well as the overall health of the obese individual. These consequences are not only related to (unhealthy) dieting behavior. Individuals might be prone to make more risky treatment decisions $[63,64]$ or fall for potentially harmful commercial dietary medications that lack evidence of effectiveness [65]. Unrealistic goals might also lead to disappointments when goals cannot be reached, and, in the worst case, this could provoke weight regain due to maladaptive eating patterns or eating disorders that arise from frustration and psychological distress [66] resulting in even more negative psychological consequences [67]. Moreover, research has shown that even weight reduction methods that can lead to greater weight loss, such as bariatric or metabolic surgery, can bring out stigmatization in response to choosing this particular method [68-70]. One possible psychological effect of not meeting one's (unrealistic) goals or expectations might be that it is interpreted as failure by the patients themselves, doubling the internalized stigma, such as 'I never put in enough effort'. Even if some research suggests that high weight loss goals can act as a successful motivator for individuals who are trying to lose weight, it remains clear that optimism might 
belinked to positive outcomes; however, whenever optimistic goals turn out to be unachievable, it can be costly [71]. Based on self-determination theory, it may make a difference whether the drive to lose weight comes from intrinsic motivation (i.e., improving health, feeling more comfortable) or in reaction to social pressure (i.e., perceived discrimination) and whether this pressure is related to losing weightand maintaining health or tied to achieving certain objective indicators of weight loss success ('a specific number on a scale') [72]. As some research suggests, perceived pressure to lose weight is related social physique anxiety which in turn is negatively related to quality of life [73]. In this context, studies investigating the motivational framework of weight loss goals and possible negative long-term effects in terms of psychological outcomes such as the development of disordered eating behaviors as a result of social pressure are still lacking. Future studies could therefore include motivations or drive for weight reduction in order to assess how these might affect weight loss goals and desires. Prospective research could also focus on investigating whether stigma and body image concerns impact decision making in terms of treatment for weight loss. Improving body image and self-esteem may be a target point for intervention as both have been shown to positively affect weight maintenance of weight loss [74]. Although the predictive value of unrealistic weight loss goals on actual weight loss is low [13], developing realistic weight loss goals is part of obesity treatment simply based on the fact that realistic weight loss goals can be specifically targeted for treatment. Therefore, patients and health care provider should agree on realistic and sustainable goals beforehand $[75,76]$. In particular, weight loss goals that are determined by discrimination and social distress might be harmful for those who suffer from obesity and related comorbidities. Interventions then could include coping strategies to help patients to deal with weight discrimination and provoke intentional and healthy weight loss rather than following stigma-induced and unmindful treatment decisions. These interventions could for example include acceptance- and mindfulness-based strategies that have already been shown to be effective in reducing weight bias that patients direct at themselves [77]. Similarly, obesity treatment should also focus on body dissatisfaction, resulting in successful weight change due to positive influences on psychological correlates of healthy eating and physical activity [78].

\section{Limitations}

In our study, the discrepancy between current weight and desired weight loss is not extreme on average. It might therefore be useful to conduct a post-hoc analysis and include only participants with weight loss goals greater than what has been suggested by the guidelines. Moreover, even though results of this study were significant in terms of $p$ values, the effect sizes of the scales under investigation are relatively small. Due to the mentioned literature, we decided to focus on effect sizes only, as it measures the proportion of variance associated with the effects itself. One explanation could be that - because differences found to be significant are very small - they might only affect a certain group of patients with obesity. There could be another mediating factor (i.e., weight loss history) which influences the link between weight loss goals and weight discrimination and has not been part of this study but could be considered in future studies. Since $\eta^{2}$ is influenced by significance and the number of effects in the model [79], one way to overcome this bias in future could be to increase the sample size. Another limitation in this context is the use of self-reported weight and height. It has been reported that individuals tend to underestimate their own weight status [80,81]. However, if this was true, our results would be even more concise because the discrepancy between current weight and desired weight would be greater than reported, leading to more extreme weight loss goals. Additionally, only few participants in our sample report more than one event of weight-based discrimination. 


\section{Conclusion}

In summary, weight reduction should be free of stigmatization or social pressure and occur in a healthy and realistic way - depending on the patients' health condition (such as comorbidities), personality, and individual needs. Instead of looking for ways of losing extreme amounts of weight within a short period of time, the focus should be put on life-long weight management and prevention of overweight and obesity.

\section{Acknowledgment}

This work was supported by the Federal Ministry of Education and Research (BMBF), Germany, FKZ: 01E01501. The authors acknowledge support from the German Research Foundation (DFG) and Universität Leipzig within the program of Open Access Publishing.

\section{Disclosure Statement}

The authors declare to have no conflict of interest.

\section{References}

1 Jensen MD, Ryan DH, Apovian CM, Ard JD, Comuzzie AG, Donato KA, et al: 2013 AHA/ACC/TOS guideline for the management of overweight and obesity in adults: a report of the American College of Cardiology/American Heart Association Task Force on Practice Guidelines and The Obesity Society. Circulation 2014;129(25 suppl 2):38.

-2 Lau DC, Douketis JD, Morrison KM, Hramiak IM, Sharma AM, Ur E; Obesity Canada Clinical Practice Guidelines Expert Panel: 2006 Canadian clinical practice guidelines on the management and prevention of obesity in adults and children [summary]. CMAJ 2007;176:S1-13.

3 Wing RR, Hill JO: Successful weight loss maintenance. Annu Rev Nutr 2001;21:323-341.

-4 Rueda-Clausen CF, Ogunleye AA, Sharma AM: Health benefits of long-term weight-loss maintenance. Annu Rev Nutr 2015;35:475-516.

5 Robison J: Health at Every Size: Toward a New Paradigm of Weight and Health. MedGenMed 2005; 7:13.

-6 Tylka TL, Annunziato RA, Burgard D, Daníelsdóttir S, Shuman E, Davis C, et al: The weight-inclusive versus weight-normative approach to health: evaluating the evidence for prioritizing well-being over weight loss. J Obes 2014;2014:983495.

7 Phelan S, Nallari M, Darroch FE, Wing RR: What do physicians recommend to their overweight and obese patients? J Am Board Fam Med 2009;22:115-122.

8 Foster GD, Wadden TA, Vogt RA, Brewer G: What is a reasonable weight loss? Patients' expectations and evaluations of obesity treatment outcomes. J Consult Clin Psychol 1997;65:79-85.

-9 Foster GD, Wadden TA, Phelan S, Sarwer DB, Sanderson RS: Obese patients' perceptions of treatment outcomes and the factors that influence them. Arch Intern Med 2001;161:2133-2139.

10 Dutton GR, Perri MG, Dancer-Brown M, Goble M, van Vessem N: Weight loss goals of patients in a health maintenance organization. Eat Behav 2010;11:74-78.

11 Fabricatore AN, Wadden TA, Womble LG, Sarwer DB, Berkowitz RI, Foster GD, et al: The role of patients' expectations and goals in the behavioral and pharmacological treatment of obesity. Int J Obes (Lond) 2007;31: 1739-1745.

-12 Wamsteker EW, Geenen R, Zelissen PMJ, van Furth EF, Iestra J: Unrealistic weight-loss goals among obese patients are associated with age and causal attributions. J Am Diet Assoc 2009;109:1903-1908.

13 Durant NH, Joseph RP, Affuso OH, Dutton GR, Robertson HT, Allison DB: Empirical evidence does not support an association between less ambitious pre-treatment goals and better treatment outcomes: a meta-analysis. Obes Rev 2013;14:532-540.

14 Elfhag K, Rossner S: Who succeeds in maintaining weight loss? A conceptual review of factors associated with weight loss maintenance and weight regain. Obes Rev 2005;6:67-85.

15 Olson EA, Visek AJ, McDonnell KA, DiPietro L: Thinness expectations and weight cycling in a sample of middleaged adults. Eat Behav 2012;13:142-145.

-16 Field AE, Manson JE, Taylor CB, Willett WC, Colditz GA: Association of weight change, weight control practices, and weight cycling among women in the Nurses' Health Study II. Int J Obes Relat Metab Disord 2004;28:11341142. 
Jung et al.: Impact of Weight-Related Discrimination, Body Dissatisfaction and Self-

Stigma on the Desire to Weigh Less

17 Muennig P, Jia H, Lee R, Lubetkin E: I think therefore I am: perceived ideal weight as a determinant of health. Am J Public Health 2008;98:501-506.

-18 Evans EH, Boothroyd LG, Muscariello E, Stephan BCM, Nasti G, Colantuoni A, et al: Lower weight loss expectations and healthier eating attitudes in older overweight and obese women attempting weight loss. Clin Obes 2015;5:136-144.

19 Levy AS, Heaton AW: Weight control practices of U.S. adults trying to lose weight. Ann Intern Med 1993;119: 661-666.

-20 Sarwer DB, Thompson JK, Cash TF: Body image and obesity in adulthood. Psychiatr Clin North Am 2005;28: 69-87, viii.

21 Siervo M, Montagnese C, Muscariello E, Evans E, Stephan BCM, Nasti G, et al: Weight loss expectations and body dissatisfaction in young women attempting to lose weight. J Hum Nutr Diet 2014;27(suppl 2):84-89.

22 Roy M, Gauvin L: Associations between different forms of body dissatisfaction and the use of weight-related behaviors among a representative population-based sample of adolescents. Eat Weight Disord 2013;18: 61-73.

23 Fabricatore AN, Wadden TA, Rohay JM, Pillitteri JL, Shiffman S, Harkins AM, et al: Weight loss expectations and goals in a population sample of overweight and obese US adults. Obesity (Silver Spring) 2008;16(11):2445-50.

-24 Stice E, Maxfield J, Wells T: Adverse effects of social pressure to be thin on young women: an experimental investigation of the effects of 'fat talk'. Int J Eat Disord 2003;34:108-117.

25 Farrow CV, Tarrant M: Weight-based discrimination, body dissatisfaction and emotional eating: the role of perceived social consensus. Psychol Health 2009;24:1021-1034.

-26 Annis NM, Cash TF, Hrabosky JI: Body image and psychosocial differences among stable average weight, currently overweight, and formerly overweight women: the role of stigmatizing experiences. Body Image 2004;1:155-167.

-27 Carels RA, Burmeister J, Oehlhof MW, Hinman N, LeRoy M, Bannon E, et al: Internalized weight bias: ratings of the self, normal weight, and obese individuals and psychological maladjustment. J Behav Med 2013;36:86-94.

-28 Pearl RL, Puhl RM, Dovidio JF: Differential effects of weight bias experiences and internalization on exercise among women with overweight and obesity. J Health Psychol 2015;20:1626-1632.

29 Schvey NA, White MA: The internalization of weight bias is associated with severe eating pathology among lean individuals. Eat Behav 2015;17:1-5.

-30 Durso LE, Latner JD: Understanding self-directed stigma: development of the weight bias internalization scale. Obesity (Silver Spring) 2008;16(suppl 2):S80-86.

-31 Durso LE, Latner JD, Ciao AC: Weight bias internalization in treatment-seeking overweight adults: Psychometric validation and associations with self-esteem, body image, and mood symptoms. Eat Behav 2016;21: 104-108.

32 Puhl RM, Heuer CA: The stigma of obesity: a review and update. Obesity (Silver Spring) 2009;17:941-964.

-33 Puhl R, Brownell KD: Bias, discrimination, and obesity. Obes Res 2001;9:788-805.

34 Sutin AR, Terracciano A: Perceived weight discrimination and obesity. PLoS One 2013;8:e70048.

-35 Ashmore JA, Friedman KE, Reichmann SK, Musante GJ: Weight-based stigmatization, psychological distress, \& binge eating behavior among obese treatment-seeking adults. Eat Behav 2008;9:203-209.

-36 Seacat JD, Mickelson KD: Stereotype threat and the exercise/dietary health intentions of overweight women. J Health Psychol 2009;14:556-567.

37 Benecke A, Vogel H: Overweight and Obesity. Berlin, Robert-Koch-Institut, 2003.

-38 Hilbert A, Baldofski S, Zenger M, Lowe B, Kersting A, Braehler E: Weight bias internalization scale: psychometric properties and population norms. PLoS One 2014;9:e86303.

-39 Hilbert A, Braehler E, Haeuser W, Zenger M: Weight bias internalization, core self-evaluation, and health in overweight and obese persons. Obesity (Silver Spring) 2014;22:79-85.

-40 Williams DR, Yan Y, Jackson JS, Anderson NB: Racial differences in physical and mental health: socio-economic status, stress and discrimination. J Health Psychol 1997;2:335-351.

41 Essed P: Understanding Everyday Racism: An Interdisciplinary Study. Sage Series on Race and Ethnic Relations, vol 2. Newbury Park, Sage Publications, 1991.

42 Feagin JR: The continuing significance of race: antiblack discrimination in public places. Am Sociol Rev 1991; 56:101-116.

-43 Myers A, Rosen JC: Obesity stigmatization and coping: relation to mental health symptoms, body image, and self-esteem. Int J Obes Relat Metab Disord 1999;23:221-230.

44 Brown TA, Cash TF, Mikulka PJ: Attitudinal body-image assessment: factor analysis of the Body-Self Relations Questionnaire. J Pers Assess 1990;55:135-144.

45 Cash TF: The MBSRQ Users' Manual. 3rd ed (Unpublished manual). Norfolk, 2000.

46 Mühlan H, Schmidt S: MBSRQ. Multidimensional Body-Self Relations Questionnaire - Deutsche Version. Göttingen, Hogrefe, 2006.

47 Vossbeck-Elsebusch AN, Waldorf M, Legenbauer T, Bauer A, Cordes M, Vocks S. German Version of the Multidimensional Body-Self Relations Questionnaire - Appearance Scales (MBSRQ-AS): confirmatory factor analysis and validation. Body Image 2014;11:191-200.

48 StataCorp LP: Stata Statistical Software (version 13 for Windows). College Station, 2014.

49 World Health Organization: Obesity: Preventing and Managing the Global Epidemic. WHO Technical Report Series 894,Geneva, World Health Organization, 2000. 
50 Smithson M: Correct confidence intervals for various regression effect sizes and parameters: the importance of noncentral distributions in computing intervals. Educ Psychol Meas 2001;61:605-632.

51 Cohen J (ed): Statistical Power Analysis for the Behavioral Sciences. Hillsdale, Erlbaum Associates, 1988.

52 Miles J, Shevlin M (ed): Applying Regression and Correlation: A Guide for Students and Researchers. London, SAGE Publications,2001.

53 Spahlholz J, Baer N, Konig H-H, Riedel-Heller SG, Luck-Sikorski C: Obesity and discrimination - a systematic review and meta-analysis of observational studies. Obes Rev 2016;17:43-55.

54 Brownell KD, Wadden TA: Etiology and treatment of obesity: understanding and treating obesity: a serious, prevalent, and refractory disorder. J Consul Clin Psychol 1992;60:505-517.

55 Brownell KD: Personal responsibility and control over our bodies: when expectation exceeds reality. Health Psychol 1991;10:303-310.

-56 Fairburn CG, Cooper Z, Shafran R: Cognitive behaviour therapy for eating disorders: a 'transdiagnostic' theory and treatment. Behav Res Ther 2003;41:509-528.

57 Fairburn CG, Wilson GT: Binge Eating: Nature, Assessment, \& Treatment. New York, The Guilford Press, 1993.

58 Stice E, Agras WS: Predicting the onset and remission of bulimic behaviors in adolescence: A longitudinal grouping analysis. Behav Ther 1998;:257-276.

59 Pearl RL, Wadden TA, Hopkins CM, Shaw JA, Hayes MR, Bakizada ZM, et al: Association between weight bias internalization and metabolic syndrome among treatment-seeking individuals with obesity. Obesity (Silver Spring) 2017;25:317-322.

-60 O’Brien KS, Latner JD, Puhl RM, Vartanian LR, Giles C, Griva K, et al: The relationship between weight stigma and eating behavior is explained by weight bias internalization and psychological distress. Appetite 2016;102: $70-76$.

-61 Durso LE, Latner JD, White MA, Masheb RM, Blomquist KK, Morgan PT, et al: Internalized weight bias in obese patients with binge eating disorder: associations with eating disturbances and psychological functioning. Int J Eat Disord 2012;45:423-427.

-62 Latner JD, Barile JP, Durso LE, O’Brien KS: Weight and health-related quality of life: the moderating role of weight discrimination and internalized weight bias. Eat Behav 2014;15:586-590.

63 Sharma S, Wharton S, Forhan M, Kuk JL: Influence of weight discrimination on weight loss goals and selfselected weight loss interventions. Clin Obes 2011;1:153-160.

64 Wee CC, Jones DB, Davis RB, Bourland AC, Hamel MB: Understanding patients' value of weight loss and expectations for bariatric surgery. Obes Surg 2006;16:496-500.

65 Bray GA, Frühbeck G, Ryan DH, Wilding JPH: Management of obesity. Lancet 2016;387:1947-1956.

66 Tomiyama AJ: Weight stigma is stressful. A review of evidence for the Cyclic Obesity/Weight-Based Stigma model. Appetite 2014;82:8-15.

-67 Foreyt JP, Brunner RL, Goodrick GK, Cutter G, Brownell KD, St Jeor ST: Psychological correlates of weight fluctuation. Int J Eat Disord 1995;17:263-275.

68 Mattingly BA, Stambush MA, Hill AE: Shedding the pounds but not the stigma: negative attributions as a function of a target's method of weight loss. J Applied Biobehav Res 2009;14:128-144.

69 Vartanian LR, Fardouly J: The stigma of obesity surgery: negative evaluations based on weight loss history. Obes Surg 2013;23:1545-1550.

70 Carels RA, Rossi J, Borushok J, Taylor MB, Kiefner-Burmeister A, Cross N, et al: Changes in weight bias and perceived employability following weight loss and gain. Obes Surg 2015;25:568-570.

71 Peterson C: The future of optimism. Am Psychol 2000;55:44-55.

-72 Teixeira PJ, Silva MN, Mata J, Palmeira AL, Markland D: Motivation, self-determination, and long-term weight control. Int J Behav Nutr Phys Act 2012;9:22.

-73 Gillison FB, Standage M, Skevington SM: Relationships among adolescents' weight perceptions, exercise goals, exercise motivation, quality of life and leisure-time exercise behaviour: a self-determination theory approach. Health Educ Res 2006;21:836-847.

-74 Foster GD, Phelan S, Wadden TA, Gill D, Ermold J, Didie E: Promoting more modest weight losses: a pilot study. Obes Res 2004;12:1271-1277.

75 Dwyer JT, Melanson KJ, Sriprachy-anunt U, et al: Dietary treatment of obesity. (updated 2015 Feb 28); in De Groot LJ, Chrousos G, Dungan K, et al. (eds): Endotext [Internet]. South Dartmouth, MDText.com, Inc, 2000.

-76 Ratcliffe D, Ellison N: Obesity and internalized weight stigma: a formulation model for an emerging psychological problem. Behav Cogn Psychother 2015;43:239-52.

77 Lillis J, Hayes SC, Bunting K, Masuda A: Teaching acceptance and mindfulness to improve the lives of the obese: a preliminary test of a theoretical model. Ann Behav Med 2009;37:58-69.

-78 Annesi JJ: Mediation of the relationship of behavioural treatment type and changes in psychological predictors of healthy eating by body satisfaction changes in women with obesity. Obes Res Clin Pract 2017;11:97-107.

79 Tabachnik BG, Fidell LS (eds): Using Multivariate Statistics, 5th ed. Upper Saddle River, Pearson Allyn \& Bacon, 2001.

-80 Lopuszanska M, Lipowicz A, Kolodziej H, Szklarska A, Bielicki T: Self-reported versus measured body height and weight in Polish adult men: the risk of underestimating obesity rates. Anthropol Anz 2015;72:263-277.

-81 Bowring AL, Peeters A, Freak-Poli R, Lim MS, Gouillou M, Hellard M: Measuring the accuracy of self-reported height and weight in a community-based sample of young people. BMC Med Res Methodol 2012;12:175. 